\title{
Bridge or ravine?
}

\section{Ideas that cross the border between scientists and non-scientists do not always survive the trip.}

\section{George and Eva Klein}

A few years ago, the British Psychoanalytical Society invited one of us to participate in a dialogue about biology. The first question was about apoptosis, or programmed cell death. "Would you not agree," went the question, "that the existence of a suicidal program that could be activated in any cell proves the ageing Freud's theory about a 'death wish' (Todeswunsch)?" I replied that apoptosis is more concerned with the life of an organism than with its death. A caterpillar would never turn into a butterfly, nor a tadpole into a frog, without extensive apoptosis in tissues that are no longer needed. We would all die of leukaemia or lymphoma at an early age if our lymphocytes - engaged as they are in a gigantic Monte Carlo game of immunoglobulin or T-cell-receptor rearrangement that allows us to react against a vast number of proteins — failed to eliminate the large majority that do not encounter their complementary antigen within a limited period of time. Apoptosis has nothing to do with the Freudian concept, except for sharing the misleading word 'death'.

Words tossed between C. P. Snow's 'two cultures' - scientists and non-scientists may lead to more serious confusion than a little misunderstanding about apoptosis. Meeting a linguist friend at a social gathering, we came to speak about Luigi CavalliSforza's studies on genetic markers in human populations and the derived conjectures about prehistoric migrations. Our friend said that he was well aware of this work and found it very beautiful, but that the conclusion that early human culture migrated with the genes was "unacceptable nonsense" because it could promote racism. I tried to explain that "culture" refers mainly to agriculture and that the absence of efficient information transfer across tribal and language barriers in prehistoric society made it understandable that new technologies arising in one location would be spread mainly by movements of people and therefore genes.

Our continued conversation made it clear, however, that my linguist colleague took Cavalli-Sforza's conclusion to imply that human culture is due to superior genes. He failed to see that the genetic markers used in these studies were merely flags. Many of them were not even genes, but polymorphic sites in non-coding DNA. My inability to convince my friend indicated to me that the Nazi mythology of superior and inferior

\section{$\sqrt{\text { ords tossed }}$ \\ C. P. Snow's 'two cultures' may lead to serious confusion.}

races may still cast its shadow over dialogue between biologists and non-biologists.

The notorious and much-abused misunderstanding between the two worlds revolves around the word 'chance'. Richard Dawkins's highly enjoyable and informative popular books about evolution, such as The Blind Watchmaker, have still left many of those who prefer to live in a pre-darwinian world unconvinced. They prefer the eighteenth-century theologian William Paley's dictum that no watch could be made 'by accident' and without a watchmaker. If they would only read Dawkins, they would see why the notion of darwinian evolution is 'counterintuitive'.

They might also consult a more recent book by the same author, Climbing Mount Improbable. In this book, Dawkins compares all existing organisms to mountain-tops. Each of them has attained its elevated position through a long series of mutations - incomprehensibly long for our subjective concept of time, which is moulded to fit our limited lifespan. Each new mutant had to pass through the needle's eye of selection, not once, but continuously over many millions of years. 'Mount Improbable' has a precipitous, almost perpendicular wall with forbidding cliffs to the north and gentle, grass-covered slopes to the south. Critics of evolution often argue against the role of 'chance', as if evolutionary theory would claim that each species reached the top by jumping from the plain to the peak in a single, randomly occurring leap. No biologist claims anything like that. They envisage a slow uphill walk along the gentle slope. The title of Jacques Monod's classical book Chance and Necessity catches the essence of the process. 'Chance' refers to random mutations, whereas 'necessity' represents the selective survival of the fittest. Mutations only provide the basis for what can happen; selection decides what actually prevails. To talk about chance alone is to miss the point.

Do biologists run the risk of serious misconceptions in their relationship with the humanities and the social sciences? In conversations with molecular biologists of

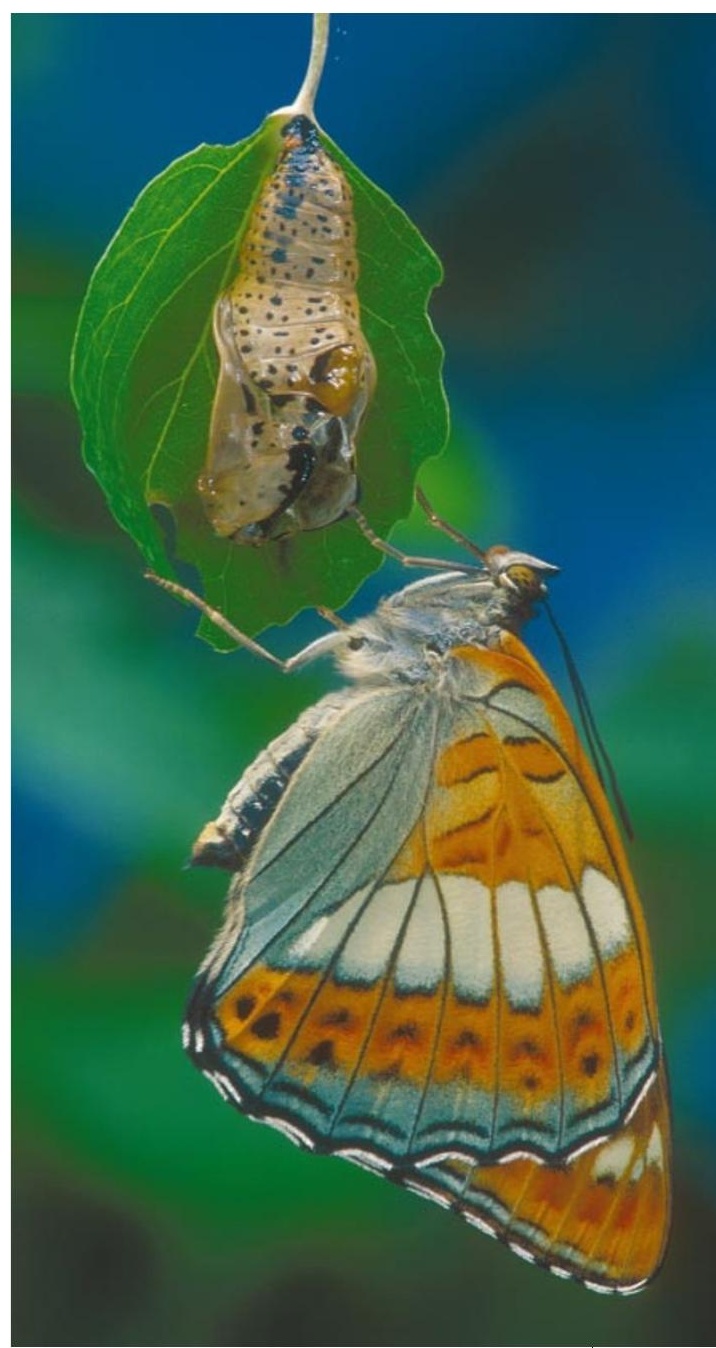

Peak of perfection: non-biologists do not always understand how organisms reach the summit.

different ages, we sometimes encounter the opinion that a detailed molecular understanding of the central nervous system and its function will render most of the social sciences and humanities, including linguistics, psychology and even poetry, superfluous. In our own conversations, we refer to this view as 'molecular fundamentalism'.

We know that all human culture stems from the activities of our neurons and the organization of our brain. But while engaging in the mandatory reductionistic analysis without which there can be no science, we must remember that the whole is more than the sum of its parts. Each new level of complexity has a distinctive world made up of its terminology, its way of reasoning, its modus operandi. We must resist the fundamentalistic temptation to believe that the 'words' of the system - that is, the molecules that provide the basis of its structure and function - can also explain the potentially infinite number of complex 'sentences' and other superstructures that our brain has built with them.

George and Eva Klein are at the Microbiology and Tumor Biology Center, Karolinska Institute,

Stockholm S-17177, Sweden. 